which may contain clues which would help us. After all, as one of the contributors to Marine Bio-acoustics points out, man's ear is probably atrophied compared with that of animals, but even we can estimate by ear the size of a room in which we are speaking, and we are remarkably good at picking out the sounds we wish to hear from a noisy background.

The subject is also, of course, extremely interesting from an academic point of view, and has important civilian applications. For example, some recent South African work on the hearing of sharks is part of a longterm programme to develop shark-repellent systems. However, most of the money is undoubtedly made avail. able, particularly in the United States, because of the potential military importance.

Tho subject is at present in an exciting state. The considerable amount of work which has been done so far has raised a numbor of interesting questions, without, in many cases, providing more than a hint at the answers. For example, some of the sounds picked up are almost certainly used for echo-location purposes, but are of a complex form the purpose of which we do not fully understand.

A symposium on "Marine Bio-Acoustics" was held at the Lerner Marine Laboratory, Bimini, Bahamas, during April 11-13, 1963. Marine Bio-acoustics incorporates 23 of the papers presented at the symposium, together with the discussion. The papers are collected into five categories. The first deals with a large underwater acoustic-video system installed at the Lerner Marine Laboratory, the second category deals with physical and acoustic aspects, the third with biological sound producers in the sea, the fourth with marine fishes as acoustic detectors, and the fifth with the special acoustic problems of cetacean research. The book forms a very useful survey of the present state of this subject.

All the contributors to this sympesium were from American organizations. Although the United States has almost a monopoly in this field, some useful work is being done in other countries.

M. J. TUCKen

\section{JORDAN'S FISH GENERA}

The Genera of Fishes and a Classification of Fishes By David Starr Jordan. Pp. xvi+800. (Stanford, California: Stanford University Press; London: Oxford University Press, 1963.) 140s. net.

D. S. JORDAN'S four classic papers entitled "The Genera of Fishes" and their taxonomic index "A Classification of Fishes" have been out of print and difficult to obtain for more than thirty years. Their reappearance as a single, moderately priced volume will receive a wide welcome.

Jordan practised as a taxonomist during a period when there was no international agreement on nomenclatural procedure. His monumental work on the fishes of north and middle America brought him face to face with innumerable problems of nomenclature and it seems likely that this experience more than any other was responsible for the "Gonera". In effect, these papers were an attempt to bring some stability into zoological nomenclature. Further, as Prof. Myers emphasizes in his admirable introduction to the reprint, the "Genera" had the immediate purpose of bringing the acceptance and application of fish generic names into accordance with the Paris 'Rules' (1905) by selecting a nomenclatural type species for every genus. In this respect the "Genera" was perhaps a little premature. It was published before methods of applying the 'Rules' were widely understood and before zoologists had benefited from the International Commissions' Opinions published in 1920. 'Thus, the terms Jordan used to indicate the different methods by which a type species name was designated or recognized were not so exact or mutually exclusive as the futuro workers required. Consequently, these categories have never been adopted and have gradually fallen into disuse.

Be that as it may, Jordan's "Genera" is still an essential first reference to be consulted in any nomenelatural tangle; present-day fish taxonomists should gratefully" recognize its importance in the history of their subject. Few works in zoology can have contributed so much to the stability of nomenclature or done so much of the essential spadework for succeeding workers.

Each of the four parts of the "Genera" deals chronologically and by alphabetically arranged authorship with the generic names proposed during the period it covers. For each genus a full bibliographical reference is given, and a type species selected according to the scheme defined in the second part. The total period covered is from 1758 to 1920 . In the first part Jordan was assisted by his colleague, E. B. Fvermann, who, it is thought, was largely responsible for the format and layout; later parts were the sole responsibility of Jordan. Inevitably in a work of this scope there are mistakes and omissions, but ono cannot help but bo impressed by their infrequency.

"A Classification of Fishes" was first published three year's after the fourth part of the "Genera" (which covered the period 1881-1920). It had a dual purpose: to list in their families all generie names of fishes, living and fossil, published since the inception of binominal nomenclatur $\theta$ and, secondly, to produce a new arrangement of fishes in their natural groups.

As a classification it was not entirely satisfactory, par. ticularly since it contained few definitions of the groups involved and little discussion of their interrelationships. It was, in fact, largely a re-interpretation of Regan's classification. Unfortunately, Jordan did not justify the emendments he made and the modern student must remain ignorant of, and intrigued by, Jordan's reasons for disagreeing with Regan in those places where the two systems diverge. As a taxonomic bibliography the "Classification" remains unique and, despite the limitations imposed on it by the growth of ichthyological literature, an invaluable reference work. It is particularly valuable for the newcomer wishing to 'place' some genus he has encountered for the first time. The principal limitation to its use in this way was the lack of a single alphabetical index covering both the "Crenera" and the "Classification". The four separate parts of the "Genera" each had an index, as did the "Classification". In the reprint edition, however, the several indexes have been omitted, to be replaced by a single comprehensive index based on a manuscript compiled by L. P. Schultz and the late H. M. Smith. The new index, now available for the first time, is a great holp, for it serves also to correct misspellings in the text, to place genera omitted by Jordan from the "Classification" although included in the "Genera", and, finally, to put in their correct families some genera misplaced in the original publications.

Prof. Myers has greatly enhanced the value of the reprint by his informative introduction which not only reviews the historical importance of Jordan's five great works but also sets them in their present perspective and thus instructs in their correct use. Prof. Myers regrets that it has not been possible to revise, correct and bring up to date the work so as to cover the forty years of research since its publication. His remarks on this subject illustrate both the vigorous growth of ichthyology and particularly the awful stature of David Starr Jordan: "However, no one has been found with both the ability and the time to carry through such an extensive revision". It is with humility that modern zoologists should remember that the "Genera" and the "Classification" were but five works from a bibliography of more than 1,900 titles of which 645 were papers devoted to fishes; the others covered such diverse subjects as education, international affairs, philosophy, poetry and even children's books.

P. H. GREENWOOD 